Hardefeldt Laura (Orcid ID: 0000-0001-5780-7567)

Crabb Helen (Orcid ID: 0000-0001-5550-3834)

\title{
Appraisal of the Australian Veterinary Prescribing Guidelines for antimicrobial prophylaxis for surgery in dogs and cats
}

LY Hardefeldt ${ }^{\mathrm{a}}$, HK Crabb ${ }^{\mathrm{a}}$, KE Bailey ${ }^{\mathrm{a}}$, T Johnstone ${ }^{\mathrm{b}}$, JR Gilkerson ${ }^{\mathrm{a}}$, H Billman-Jacobe ${ }^{\mathrm{a}}$, GF

Browning $^{\mathrm{a}}$

${ }^{a}$ Asia-Pacific Centre for Animal Health, Melbourne Veterinary School, University of Melbourne and the National Centre for Antimicrobial Stewardship, Peter Doherty Institute, Grattan St, Carlton 3050, Victoria, Australia

b Translational Research and Animal Clinical Trial Study Group (TRACTS), U-Vet Animal Hospital Werribee, Faculty of Veterinary and Agricultural Sciences, The University of Melbourne, 250 Princes Hwy, Werribee 3030, Victoria, Australia

Corresponding author:

Laura Hardefeldt

Veterinary Preclinical Centre

University of Melbourne

Parkville, VIC, AUSTRALIA 3052

Laura.hardefeldt@unimelb.edu.au

\begin{abstract}
The Australian Veterinary Prescribing Guidelines for antimicrobial prophylaxis for surgery on dogs and cats are evidence-based guidelines for veterinary practitioners. Validation of these guidelines is necessary to ensure quality and implementability. Two validated tools, used for medical guideline appraisal, were chosen to assess the guidelines. The terminology from the GuideLine
\end{abstract}

This is the author manuscript accepted for publication and has undergone full peer review but has not been through the copyediting, typesetting, pagination and proofreading process, which may lead to differences between this version and the Version of Record. Please cite this article as doi: $10.1111 /$ avj.12848

This article is protected by copyright. All rights reserved. 
Implementability Appraisal (GLIA) and the Appraisal of Guidelines for Research and Evaluation version 2 (AGREE II) were adapted for use by veterinarians. A two-phase evaluation approach was conducted. In the first phase of the evaluation, the GLIA tool was used by two specialist veterinary surgeons in clinical practice. The results of this phase were then used to modify the guidelines. In the second phase, the AGREE II tool was used by 6 general practitioners and 6 specialists to appraise the guidelines. In phase 1, the specialist surgeons either agreed or strongly agreed that the guidelines were executable, decidable, valid and novel, and that the guidelines would fit within the process of care. The surgeons were neutral on flexibility and measurability. Additional clarity around one common surgical procedure was added to the guidelines, after which the surgeons agreed that the guidelines were sufficiently flexible. In phase 2, 12 veterinarians completed the assessment using the AGREE II tool. In all sections the scaled domain score was greater than $70 \%$. The overall quality of the guidelines was given a global scaled score of $76 \%$. This assessment has demonstrated that the guidelines for antimicrobial prophylaxis for companion animal surgery are valid and appear implementable.

\title{
Keywords
}

Antimicrobial stewardship; companion animals; antibiotic; resistance

\author{
Abbreviations \\ Antimicrobial resistance, AMR; International Society for Companion Animal Infectious Diseases, \\ ISCAID; GuideLine Implementability Appraisal, GLIA; Appraisal of Guidelines for Research and \\ Evaluation version 2, AGREE II
}

\section{Introduction}

This article is protected by copyright. All rights reserved. 
Antimicrobial resistance (AMR) is a global health emergency. Antimicrobial prescribing by veterinarians contributes, at least, to resistance of pathogens in animals, ${ }^{1}$ and in some cases to AMR in the human community. ${ }^{2}$ Antimicrobial stewardship is "a coherent set of actions which promote using antimicrobials responsibly" with the overall goals of improving health outcomes for patients and reducing the adverse effects of antimicrobial use, such as AMR. These actions have, in medical practice, been largely based around efforts to align antimicrobial prescribing with antimicrobial use guidelines. ${ }^{4}$

Veterinary antimicrobial use guidelines are in varying stages of development globally. Guidelines have been developed by special interest groups (the International Society for Companion Animal Infectious Diseases ${ }^{5}$ [ISCAID]), representative veterinary bodies (e.g. the British Small Animal Veterinary Association, ${ }^{6}$ the Danish Small Animal Veterinary Association ${ }^{7}$ ) and by other groups with the support of pharmaceutical companies (the Australasian Infectious Disease Advisory $\operatorname{Panel}^{8}$ ). With the exception of ISCAID, ${ }^{9-11}$ no group has pursued a peer-review process to improve the validity of their guidelines and their implementability has not been assessed. The availability of antimicrobial products differs between countries and different rates of AMR between companion animal species have a large impact on local antimicrobial use recommendations and prohibit automated implementation of international antimicrobial use guidelines (such as ISCAID) at the national level. In response to a lack of independent guidelines in Australia, the Australian Veterinary Prescribing Guidelines for surgical prophylaxis in dogs and cats (Summary provided in Table 1, complete guidelines available at www.fvas.unimelb.edu.au/vetantibiotics) were created by the University of Melbourne's Asia-Pacific Centre for Animal Health and the National Centre for Antimicrobial Stewardship. The guidelines serve as an independent source of guidelines for practitioners, and the veterinary profession, with the overall goal of improving appropriate 
antimicrobial use and reducing pressure on the development of antimicrobial resistance in veterinary practice.

A peer-reviewed appraisal process may improve confidence in the guidelines and promote appropriate antimicrobial use. Therefore, the aim of this study was to undertake such a process to assess the validity and implementability of the companion animal antimicrobial use guidelines for surgical prophylaxis.

\section{Methods}

No veterinary specific appraisal tools are currently available for veterinary guidelines. A review of the medical guideline appraisal tools was undertaken in order to identify tools for which efficacy had been assessed. Two validated and widely used tools were chosen. In both cases the terminology of the appraisal tool had to be modified to ensure the tool was appropriate for a veterinary audience. The GuideLine Implementability Appraisal ${ }^{12}$ (GLIA) has 7 sections, covering executability, decidability, validity, flexibility, effect on process of care, measurability and novelty, and a global guideline assessment (26 closed and 14 open questions) and uses a Likert-like scale from strongly agree to strongly disagree (Supplementary table 1). The tool is recommended for use by guideline developers for application of the results to remedy defects in their guidelines and for guideline implementers to identify barriers to implementation. ${ }^{13}$ In the first phase of the evaluation, the GLIA tool was used by specialist surgeons to evaluate the guidelines for use in clinical surgical practice. Specialist surgeons were recruited through the Australian and New Zealand College of Veterinary Surgeons, by contacting university surgeons. Only 2 surgeons were willing to be involved. These surgeons were not involved in the development of the guidelines and had no knowledge of the guidelines prior to their recruitment into the appraisal project. In addition to the guidelines (Table 1), supporting material used 
in the development of the guidelines was made available to the surgeons and is available on the webpage under the tab "See the evidence.” The results of this phase were then used to modify the guidelines for further assessment.

The Appraisal of Guidelines for Research and Evaluation version $2^{14}$ (AGREE II) has 6 domains, covering the scope and purpose of the guidelines, stakeholder involvement, rigour of development, clarity of presentation, applicability and editorial independence, and an overall guideline assessment (25 closed and 24 open questions). The tool was developed to address the issue of variability in the quality of practice guidelines and has been adopted internationally to evaluate clinical medical guidelines. The AGREE II items and the two overall rating items were rated on a 7-point scale $(1=$ strongly disagree to 7 = strongly agree). A score was assigned, depending on the completeness and quality of reporting. Domain scores were calculated by summing the scores for the individual items in each domain and scaling the total as a percentage of the maximum possible score for that domain. The scaled domain score was calculated as: (obtained score-minimum possible score)/(maximum possible score-minimum possible score). Scores greater than 85, between 70 and 84 and less than 70 reflected strong, moderate and weak agreement, respectively.

This tool was used in the second phase by a panel of 12 veterinarians, including surgery specialists from private practice, practitioners from companion animal and mixed species general practice, and non-surgical specialists with an interest in infectious diseases or antimicrobial stewardship. Neither specialist who completed phase 1 participated in phase 2 of the evaluation process. Non-surgical specialists were recruited from the VSANZ panel of AMS experts that were involved in the creation of the VSANZ/DAWR AMS learning modules, with representatives from all universities invited. General practitioners were recruited by advertising on social media, from practices participating in an AMS trial and through referrals from general practitioners who had completed the appraisal. In 
addition to the guidelines (Table 1), supporting material used in the development of the guidelines was made available to the appraisers and is available on the webpage under the tab "See the evidence.”

The appraisals were conducted using REDCap electronic data capture tools. ${ }^{15}$ Both tools are available as supplementary information. Appraisal data were downloaded into spreadsheets (Microsoft Office Excel, 2016). Conventional content analysis ${ }^{16}$ was used to evaluate responses to the open questions.

This research was approved by the University of Melbourne Faculty of Veterinary and Agricultural Sciences Human Research Ethics Advisory Group under approval number 1750588.1.

\section{Results}

In the first phase of the review, specialist surgeons (2) either agreed or strongly agreed that the guidelines were executable, decidable, valid and novel, and that the guidelines would fit within the process of care. Completion of the GLIA tool took around 1-2 hours. The surgeons were neutral on flexibility and requested extra clarity around surgical treatment of cranial cruciate ligament rupture. The reviewing surgeons felt that, as many research papers have been produced addressing surgical techniques for cranial cruciate ligament rupture and these often contained conflicting advice, this syndrome should be treated as a special case in these guidelines. The authors' agreed and a section was added with recommendations for these surgical cases (Table 1). The guideline was returned to the reviewing surgeons, after which they agreed that the guideline was flexible. The surgeons were neutral on the measurability of any change in practice. 
A total of 12 veterinarians completed the second phase of the appraisal (6 general practitioners, 2 specialist surgeons and 4 other small animal specialists with an interest in antimicrobial stewardship). Completion of the appraisal took around 1-2 hours. Domain 1 had 3 questions related to the scope and purpose of the guidelines. The scaled domain score was 86\% (Table 2). Appraisers requested further information about antimicrobial use for specific surgical scenarios (4/12), on drug dose rates (1/12) and on categorisation of surgical risk (1/12).

Domain 2 had 3 questions related to stakeholder involvement in guideline development. The scaled domain score was 73\% (Table 2). Appraisers (8/12) were unsure whether the development group included individuals from all relevant professional bodies.

Domain 3 had 8 questions related to the rigour of development of the guidelines. The scaled domain score was $80 \%$ (Table 2). Eight of the 12 appraisers thought the methods for formulating the recommendations were clearly described. Four appraisers were unsure whether the methods for formulating the recommendations were clearly described, were unsure whether the health benefits, side-effects and risks were considered in formulating the recommendations and were not sure about the procedures for updating the guidelines. Three appraisers were not sure if the guidelines had been externally reviewed prior to publication.

Domain 4 had 3 questions related to the clarity of presentation of the guidelines. The scaled domain score was $84 \%$ (Table 2). Eleven appraisers thought the clarity of presentation of the guidelines was appropriate. One appraiser requested further information on categorisation of surgical risk, with inclusion of further examples of where specific surgeries fitted into the National Research Council's index of risk for surgical infection. This has been added to the guidelines. 
Domain 5 had 4 questions related to the applicability of the guidelines. The scaled domain score was 72\% (Table 2). Nine appraisers thought the guidelines were broadly applicable. Three appraisers thought that the guidelines did not adequately describe the facilitators and barriers to their application and one appraiser thought timing of antimicrobial administration should be further emphasised. One appraiser also thought that the potential resource implications of applying the recommendations were not considered and that there was not enough detail on how to check for compliance with the guidelines or on other methods to measure guideline utilisation.

Domain 6 had 3 questions related to editorial independence. The scaled domain score was 80\% (Table 2). Eleven appraisers thought the guidelines had editorial independence. One appraiser felt that stakeholder views (i.e. pharmaceutical companies) should have been considered in the development of the guidelines.

Prior to modification, the appraisers gave the guidelines an overall score of 76\% (Table 2). Eight appraisers felt the guidelines should be published in the original form and 4 recommended modifications. Reviewers recommended details on antimicrobial doses (1/4), further detail on species and age groups (1/4), additional guidelines to accompany these guidelines (i.e. infection control) (1/4) and more detail within the guidelines on available supporting evidence (1/4). Further information on categorisation of surgical risk were added to the guidelines. The guidelines were not re-assessed following modification based on the appraisal process.

\section{Discussion}


These are the first guidelines to undergo structured review in the veterinary literature, and the only stand-alone guidelines for companion animal veterinarians on the use of antimicrobials for surgical prophylaxis in dogs and cats globally. Based on the appraisal process, the guidelines were further improved and can now be regarded as reflecting current best-practice for antimicrobial use for surgical prophylaxis in companion animal medicine.

In the first phase of the appraisal, companion animal surgeons used the GLIA tool and were unsure of the measurability of any change in prescribing practice in veterinary clinics. This reflects the wider challenge of monitoring antimicrobial stewardship in veterinary practices. Detailed antimicrobial use surveillance is conducted in Europe, but use in the companion animal sector is the least well defined area, with the emphasis placed on use in food animal species. ${ }^{17}$ There is no such surveillance currently undertaken in any animal sector in Australia. Reductions in sales of antimicrobial agents for a species have been used as evidence of success in guideline implementation, ${ }^{18}$ but appropriateness of antimicrobial use is a better measure of success and is used in the medical sector. ${ }^{19}$ Further research and innovation is needed in this area in veterinary medicine.

In the second phase of appraisal, 6 domains of the guidelines were evaluated. In domain 1 there was strong agreement that the scope and purpose of the guidelines were well described and appropriate. The appraisers requested further information about antimicrobial use for specific surgical scenarios, but evidence for use in specific surgical scenarios is lacking in the veterinary literature, with the exception of a few surgical interventions (e.g. cranial cruciate rupture). Further research is required on specific surgical scenarios to allow the development of detailed recommendations. Recommendations about drug doses were also requested, but were outside the scope of these guidelines. However, referral of readers to the appropriate sources will be considered in the future. Further information on 
categorisation of risk was requested in several sections of the appraisal and the authors agreed that examples of categorisation of surgical risk may assist veterinarians in interpreting the guidelines, so these have been added to the guidelines.

In domain 2 there was moderate agreement that there was adequate stakeholder involvement in guideline development. Appraisers were unsure whether the development group included individuals from all relevant professional bodies. The development group consisted of veterinarians from the National Centre for Antimicrobial Stewardship and the Melbourne Veterinary School. Other groups were approached but declined to participate. This represents another challenge in guideline development within the veterinary sector. Veterinarians recognise that guidelines should be independent of pharmaceutical company influence, and hence funding from these sources, ${ }^{20}$ but also recognise that they should be freely available to the profession. However, development of guidelines is time-consuming and hence expensive, and a funding source is difficult to secure. Government funding sources, such as the Medical Research Future Fund, needs to be open to the veterinary sector when solutions to One Health issues such as antimicrobial resistance and stewardship are sought.

In domain 3 there was moderate agreement that the rigour of development of the guidelines was adequate. Appraisers were unsure whether the methods for formulating the recommendations were clearly described so the authors revised this aspect in the final draft. Some appraisers were unsure whether the health benefits, side-effects and risks were considered in formulating the recommendations. These are inherent in the formulation of antimicrobial use guidelines, but these were not explicitly stated in the guidelines. The authors feel that this kind of information is better placed in the education section of the webpage, to reduce the length and hence ensure the accessibility of the guidelines. Some appraisers were also unsure whether the guidelines had been externally 
reviewed prior to publication and were not sure about the procedure for updating the guidelines. The guidelines were reviewed by 2 academic surgeons prior to publication and have now been further reviewed during the study described here. The guidelines will only remain valid as long as they are continually updated when new information becomes available. As indicated in the introduction to the guidelines $^{21}$, a process for this is already in place. In fact, users of the current guidelines are invited to suggest changes to the guidelines (through the "make a suggestion” tab). With any further revision, appraisal of major modifications to the current guidelines may also be sought.

In domain 5 there was moderate agreement that the guidelines were applicable. Appraisers disagreed that the guidelines described the facilitators for and barriers to their application. The barriers to implementation of such guidelines have not been investigated in veterinary medicine in Australia. Barriers to implementing similar guidelines have been evaluated in Denmark, with confidence in old prescribing practices, lack of availability of products, difficulties in dosing, cost, lack of time, the limited number of drugs available in practices and the difficulties owners experience in administering drugs all given as reasons for not adhering to the therapeutic recommendations. ${ }^{22}$ Similar responses seem likely to apply in Australia, although this needs further investigation and could follow full implementation of these guidelines. One appraiser thought the timing of antimicrobial administration should be further emphasised. The authors' felt that appropriate weight was given to the timing of antimicrobial therapy and this was not altered in the final draft. An appraiser also thought the potential resource implications of applying the recommendations were not considered and that there was not enough detail on how to check for compliance with the guidelines or on other methods to measure guideline utilisation. The resources required to implement the guidelines are minimal and have been provided along with the guidelines (via weblinks). Methods for monitoring compliance with guidelines are in the early stages of development in veterinary medicine and are not widely 
available. Individual practice managers and practice owners need to develop methods for checking compliance that suit their practice environment at this stage. This might include periodic review of clinical records or the use of a surgical checklist (i.e. a standardised list used to improve perioperative routine). Surgical checklists have been successfully used in veterinary practice to reduce the incidence of surgical site infections. ${ }^{23}$

In domain 6, there was moderate to strong agreement that there was editorial independence in the production of the guidelines. One appraiser felt that stakeholder views (i.e. pharmaceutical companies) should have been considered in the development of the guidelines. The authors' disagreed with the view that groups such as pharmaceutical companies should be considered in the development of guidelines to preserve the independence of the guidelines. No change was made to the guideline development process in this regard.

Overall, the appraisers gave the guidelines a scaled global evaluation of 76\%. Four appraisers recommended modifications prior to dissemination of the guidelines. These recommendations included further detail on antimicrobial doses and further detail on species and age groups. As discussed above, details on antimicrobial doses was outside the scope of these guidelines and evidence to support guidelines for specific surgical interventions is lacking, thus preventing inclusion of greater detail in the guidelines. Additional guidelines to accompany these antimicrobial use guidelines (i.e. infection control) and more detail within these guidelines of supportive evidence were also requested as modifications by reviewers. Infection control guidelines are promoted on the Australian Veterinary Prescribing Guideline website, as are other guidelines, where appropriate. 
The AGREE Enterprise recommends that 2-4 appraisers evaluate the guidelines, ${ }^{14}$ and this is common practice in human medicine. ${ }^{24-26}$ However, the authors' felt that evaluation by a wider group was warranted given the diversity in practitioner circumstances in companion animal practice in Australia. Wider evaluation of validity was also sought for the initial phase of the project, however recruitment of participants was challenging. It is possible that inclusion of additional appraisers may have identified additional gaps within the guidelines.

In conclusion, the Australian Veterinary Prescribing Guidelines on antimicrobial use for surgical prophylaxis in companion animals have performed well in the appraisal process, with moderate or strong agreement in all domains of the appraisal tool. Antimicrobial use guidelines form a critical part of antimicrobial stewardship programs and Australian veterinarians can have confidence that these guidelines have validity and are implementable in veterinary hospitals. While these guidelines present the best evidence for current surgical prophylaxis, research on appropriate prophylaxis for specific surgical situations is needed, especially for clean-contaminated and contaminated procedures. Further research is also needed into monitoring antimicrobial stewardship programs in veterinary practices.

\section{Acknowledgements}

This research was funded by the NHMRC and the National Centre for Antimicrobial Stewardship.

\section{References}

1. Beck KM, Waisglass SE, Dick HL, Weese JS. Prevalence of methicillin-resistant Staphylococcus pseudintermedius (MRSP) from skin and carriage sites of dogs after treatment of their meticillin-resistant or meticillin-sensitive staphylococcal pyoderma. Vet Dermatol 2012;23:369-375, e366-367. 
2. Dutil L, Irwin R, Finley R, Ng LK, Avery B, Boerlin P, Bourgault AM, Cole L, Daignault D, Desruisseau A, Demczuk W, Hoang L, Horsman GB, Ismail J, Jamieson F, Maki A, Pacagnella A, Pillai DR. Ceftiofur resistance in Salmonella enterica serovar Heidelberg from chicken meat and humans, Canada. Emerg Infect Dis 2010;16:48-54.

3. Dyar OJ, Huttner B, Schouten J, Pulcini C, Esgap. What is antimicrobial stewardship? Clin Microbiol Infect 2017;23:793-798.

4. Davey P, Peden C, Brown E, Charani E, Michie S, Ramsay CR, Marwick CA, Davey P. Interventions to improve antibiotic prescribing practices for hospital inpatients (updated protocol). The Cochrane Collaboration, Cochrane Database of Systematic Reviews, 2014.

5. Weese JS, Blondeau J, Boothe D, Breitschwerdt E, Guardabassi L, Hillier A, Lloyd DH, Papich MG, Rankin S, Turnidge J, Sykes JE. International Society for Companion Animal Infectious Diseases. https://iscaid.org. 2018. Retrieved 12/7/18.

6. British Small Animal Veterinary Association. PROTECT. https://www.bsavalibrary.com/content/book/10.22233/9781910443644. 2016. Retrieved 16/2/18. 7. Spohr A, Schjoth B, Wiinberg B, Houser G, Willesen J, Jesson LR, Guardabassi L, Schjaerff M, Eriksen T, Jensen VF. Antibiotic use guidelines for companion animal practice. Danish Small Animal Veterinary Association, https://www.ddd.dk/sektioner/familiedyr/antibiotikavejledning/Documents/AntibioticGuidelines\%20\%20v1.4 jun15.pdf, 2009.

8. Holloway S, Trott DJ, Shipstone M, Barrs V, Malik R, Burrows M. Antibiotic prescribing; detailed guidelines. Australasian Infectious Diseases Advisory Panel, https://www.ava.com.au/search/?q=aidap\&_t_dtq=true, 2013.

9. Weese JS, Blondeau JM, Boothe D, Breitschwerdt EB, Guardabassi L, Hillier A, Lloyd DH, Papich MG, Rankin SC, Turnidge JD, Sykes JE. Antimicrobial use guidelines for treatment of urinary 
tract disease in dogs and cats: antimicrobial guidelines working group of the international society for companion animal infectious diseases. Vet Med Int 2011;2011:263768.

10. Hillier A, Lloyd DH, Weese JS, Blondeau JM, Boothe D, Breitschwerdt E, Guardabassi L, Papich MG, Rankin S, Turnidge JD, Sykes JE. Guidelines for the diagnosis and antimicrobial therapy of canine superficial bacterial folliculitis (Antimicrobial Guidelines Working Group of the International Society for Companion Animal Infectious Diseases). Vet Dermatol 2014;25:163-175, e142-163.

11. Lappin MR, Blondeau J, Boothe D, Breitschwerdt EB, Guardabassi L, Lloyd DH, Papich MG, Rankin SC, Sykes JE, Turnidge J, Weese JS. Antimicrobial Use Guidelines for Treatment of Respiratory Tract Disease in Dogs and Cats: Antimicrobial Guidelines Working Group of the International Society for Companion Animal Infectious Diseases. J Vet Intern Med 2017;31:279-294. 12. Shiffman RN, Michel G. GLIA 2.0: GuideLine Implementability Appraisal. http://nutmeg. med.yale.edu/glia/login.htm;jsessionid=578C357235BF95070326DCE6A51ACE57. 2011. Retrieved 12/7/18.

13. Shiffman RN, Dixon J, Brandt C, Essaihi A, Hsiao A, Michel G, O'Connell R. The GuideLine Implementability Appraisal (GLIA): development of an instrument to identify obstacles to guideline implementation. BMC Med Inform Decis Mak 2005;5:23.

14. Brouwers MC, Kho ME, Browman GP, Burgers JS, Cluzeau F, Feder G, Fervers B, Graham ID, Grimshaw J, Hanna SE, Littlejohns P, Makarski J, Zitzelsberger L, Consortium ANS. AGREE II: advancing guideline development, reporting and evaluation in health care. CMAJ 2010;182:E839-842. 15. Harris PA, Taylor R, Thielke R, Payne J, Gonzalez N, Conde JG. Research electronic data capture (REDCap) - a metadata-driven methodology and workflow process for providing translational research informatics support. J Biomed Inform 2009;42:377-381.

This article is protected by copyright. All rights reserved. 
16. Hsieh HF, Shannon SE. Three approaches to qualitative content analysis. Qual Health Res 2005;15:1277-1288.

17. Hog BB, Korsgaard H, Sonksen UW. DANMAP 2016.

https://www.danmap.org/ /media/Projekt\%20sites/Danmap/DANMAP\%20reports/DANMAP\%2020 16/DANMAP_2016_web.ashx, 2017.

18. Greko C. Reduction of sales of antimicrobials for dogs - Swedish experiences. Eur J Comp Anim Pract 2013; 23:55-60.

19. Australian Commission on Safety and Quality in Health Care. AURA 2017: Second report on antimicrobial use and resistance in human health. https://www.safetyandquality.gov.au/wpcontent/uploads/2018/01/AURA-2017-Second-Australian-report-on-Antimicrobial-Use-andResistance-in-human-health.pdf, 2017.

20. Hardefeldt LY, Gilkerson JR, Billman-Jacobe H, Stevenson MA, Thursky K, Bailey KE, Browning GF. Barriers to and enablers of implementing antimicrobial stewardship programs in veterinary practices. J Vet Intern Med 2018;32:1092-1099.

21. Asia Pacific Centre for Animal Health, National Centre for Antimicrobial Stewardship. Australian Veterinary Prescribing Guidelines. www.fvas.unimelb.edu.au/vetantibiotics. 2017. Retrieved 13/9/17.

22. Jessen LR, Sorensen TM, Lilja ZL, Kristensen M, Hald T, Damborg P. Cross-sectional survey on the use and impact of the Danish national antibiotic use guidelines for companion animal practice. Acta Vet Scand 2017;59:81.

23. Bergstrom A, Dimopoulou M, Eldh M. Reduction of surgical complications in dogs and cats by the use of a surgical safety checklist. Vet Surg 2016;45:571-576.

24. Yang C, Zhang Z, Zhang L, Tian J, Yu D, Wang J, Yang J. Quality assessment of clinical practice guidelines on tic disorders with AGREE II instrument. Psychiatry Res 2018;259:385-391. 
25. Tyagi NK, Dhesy-Thind S. Clinical practice guidelines in breast cancer. Curr Oncol 2018;25:S151-S160.

26. Tamas G, Abrantes C, Valadas A, Radics P, Albanese A, Tijssen MAJ, Ferreira JJ. Quality and reporting of guidelines on the diagnosis and management of dystonia. Eur J Neurol 2018;25:275283.

27. Turk R, Singh A, Weese JS. Prospective surgical site infection surveillance in dogs. Vet Surg 2015;44:2-8.

28. Weese JS, Halling KB. Perioperative administration of antimicrobials associated with elective surgery for cranial cruciate ligament rupture in dogs: 83 cases (2003-2005). JAVMA 2006;229:92-95. 29. Vasseur PB, Paul HA, Enos LR, Hirsch DC. Infection rates in clean surgical procedures: a comparison of ampicillin prophylaxis vs a placebo. JAVMA 1985;187:825-827.

30. Mayhew PD, Freeman L, Kwan T, Brown DC. Comparison of surgical site infection rates in clean and clean-contaminated wounds in dogs and cats after minimally invasive versus open surgery: 179 cases (2007-2008). JAVMA 2012;240:193-198.

31. Eugster S, Schawalder P, Gaschen F, Boerlin P. A prospective study of postoperative surgical site infections in dogs and cats. Vet Surg 2004;33:542-550.

32. Nicholson M, Beal M, Shofer F, Brown DC. Epidemiologic evaluation of postoperative wound infection in clean-contaminated wounds: a retrospective study of 239 dogs and cats. Vet Surg 2002;31:577-581.

33. Aiken MJ, Hughes TK, Abercromby RH, Holmes MA, Anderson AA. Prospective, randomized comparison of the effect of two antimicrobial regimes on surgical site infection rate in dogs undergoing orthopedic implant surgery. Vet Surg 2015;44:661-667. 
34. Bowersock TL, Wu CC, Inskeep GA, Chester ST. Prevention of bacteremia in dogs undergoing dental scaling by prior administration of oral clindamycin or chlorhexidine oral rinse. $J$ Vet Dent 2000;17:11-16.

35. Nieves MA, Hartwig P, Kinyon JM, Riedesel DH. Bacterial isolates from plaque and from blood during and after routine dental procedures in dogs. Vet Surg 1997;26:26-32.

36. Gonzalez OJ, Renberg WC, Roush JK, KuKanich B, Warner M. Pharmacokinetics of cefazolin for prophylactic administration to dogs. Am J Vet Res 2017;78:695-701.

37. Marcellin-Little DJ, Papich MG, Richardson DC, DeYoung DJ. Pharmacokinetic model for cefazolin distribution during total hip arthroplasty in dogs. Am J Vet Res 1996;57:720-723.

38. Marier JF, Beaudry F, Ducharme MP, Fortin D, Moreau JP, Masse R, Vachon P. A pharmacokinetic study of amoxycillin in febrile beagle dogs following repeated administrations of endotoxin. J Vet Pharmacol Ther 2001;24:379-383.

39. Yap FW, Calvo I, Smith KD, Parkin T. Perioperative risk factors for surgical site infection in tibial tuberosity advancement: 224 stifles. Vet Comp Orthop Traumatol 2015;28:199-206.

40. Stauffer KD, Tuttle TA, Elkins AD, Wehrenberg AP, Character BJ. Complications associated with 696 tibial plateau leveling osteotomies (2001-2003). J Am Anim Hosp Assoc 2006;42:44-50. 41. Cook JL, Luther JK, Beetem J, Karnes J, Cook CR. Clinical comparison of a novel extracapsular stabilization procedure and tibial plateau leveling osteotomy for treatment of cranial cruciate ligament deficiency in dogs. Vet Surg 2010;39:315-323.

42. Fitzpatrick N, Solano MA. Predictive variables for complications after TPLO with stifle inspection by arthrotomy in 1000 consecutive dogs. Vet Surg 2010;39:460-474.

43. Gatineau M, Dupuis J, Plante J, Moreau M. Retrospective study of 476 tibial plateau levelling osteotomy procedures. Rate of subsequent 'pivot shift', meniscal tear and other complications. Vet Comp Orthop Traumatol 2011;24:333-341.

This article is protected by copyright. All rights reserved. 
44. Pacchiana PD, Morris E, Gillings SL, Jessen CR, Lipowitz AJ. Surgical and postoperative complications associated with tibial plateau leveling osteotomy in dogs with cranial cruciate ligament rupture: 397 cases (1998-2001). J Am Vet Med Assoc 2003;222:184-193.

45. Frey TN, Hoelzler MG, Scavelli TD, Fulcher RP, Bastian RP. Risk factors for surgical site infection-inflammation in dogs undergoing surgery for rupture of the cranial cruciate ligament: 902 cases (2005-2006). J Am Vet Med Assoc 2010;236:88-94.

This article is protected by copyright. All rights reserved. 
Table 1. Guidelines for surgical prophylaxis for companion animals

\begin{tabular}{|c|c|c|c|c|c|}
\hline $\begin{array}{c}\text { Surgical } \\
\text { contamination } \\
\text { level }\end{array}$ & $\begin{array}{l}\text { Complicating } \\
\text { factors }\end{array}$ & $\begin{array}{l}\text { Likely } \\
\text { pathogens }\end{array}$ & $\begin{array}{l}\text { Antimicrobial } \\
\text { recommendation }\end{array}$ & Duration of therapy & $\begin{array}{l}\text { Level of } \\
\text { evidence }\end{array}$ \\
\hline \multirow[t]{3}{*}{ Clean } & \multicolumn{2}{|c|}{$\begin{array}{l}\text { Only if surgical site infection } \\
\text { would be a major threat to the } \\
\text { patient (i.e. central nervous system } \\
\text { surgery) }\end{array}$} & $\begin{array}{l}\text { None } \\
\text { Amoxycillin } \\
\text { or } 1^{\text {st }} \text { generation } \\
\text { cephalosporin }\end{array}$ & Stop within 24 hours ${ }^{28}$ & Strong \\
\hline & $\begin{array}{l}\text { Hypotension } \\
\text { Surgical duratio } \\
\text { Morbidly obese } \\
\text { Endocrine disor } \\
\text { Bacterial derma }\end{array}$ & $\begin{array}{l}>90 \operatorname{mins}^{29,30} \\
\operatorname{ogs}^{31} \\
\text { er }^{32} \\
\text { is }\end{array}$ & $\begin{array}{l}\text { Amoxycillin } \\
\text { or } 1^{\text {st }} \text { generation } \\
\text { cephalosporin }\end{array}$ & $\begin{array}{l}\text { Stop within } 24 \text { hours* } \\
\text { Stop within } 24 \text { hours* } \\
\text { Stop within } 24 \text { hours* } \\
\text { Stop within } 24 \text { hours* } \\
\text { Treat till infection cured }\end{array}$ & Medium \\
\hline & Implant $^{27,33}$ & $\begin{array}{l}\text { Orthopaedic: } \\
\text { Staphylococcus } \\
\text { pseudintermedius }\end{array}$ & $\begin{array}{l}\text { Amoxycillin } \\
\text { or } 1^{\text {st }} \text { generation } \\
\text { cephalosporin }\end{array}$ & Perioperative only**33 & Medium \\
\hline $\begin{array}{l}\text { Clean } \\
\text { contaminated }\end{array}$ & Gastrointestinal & $\begin{array}{l}\text { Coliforms, } \\
\text { anaerobes if } \\
\text { caudal GI tract }\end{array}$ & $\begin{array}{l}\text { Amoxycillin } \\
\text { or } 1^{\text {st }} \text { generation } \\
\text { cephalosporin }\end{array}$ & Stop within 24 hours* & Medium \\
\hline Contaminated & $\begin{array}{l}\text { Pyometra, } \\
\text { prostatic } \\
\text { abscess }\end{array}$ & $\begin{array}{l}\text { E. coli, } \\
\text { Streptococcus } \\
\text { species, } \\
\text { anaerobes }\end{array}$ & $\begin{array}{l}\text { Amoxycillin } \\
\text { or } 1^{\text {st }} \text { generation } \\
\text { cephalosporin \& } \\
\text { gentamicin \& } \\
\text { metronidazole }\end{array}$ & $\begin{array}{l}\text { No evidence, } 24-48 \\
\text { hours is common in } \\
\text { human medicine }\end{array}$ & Weak \\
\hline & Significant & Coliforms & Amoxycillin \& & No evidence, 24-48 & Weak \\
\hline
\end{tabular}




\begin{tabular}{|c|c|c|c|c|}
\hline & bowel leakage & gentamicin & $\begin{array}{l}\text { hours is common in } \\
\text { human medicine }\end{array}$ & \\
\hline Dirty & & $\begin{array}{l}\text { Choose } \\
\text { appropriate for } \\
\text { infection (ideally } \\
\text { based on culture } \\
\text { and susceptibility } \\
\text { testing) }\end{array}$ & Treat till infection cured & \\
\hline Dental & $\begin{array}{l}\text { None } \\
\text { Geriatric patients, severe heart } \\
\text { disease, systemic illness, } \\
\text { immunosuppression }\end{array}$ & $\begin{array}{l}\text { None } \\
\text { Bacteraemia } \\
\text { expected for } \\
\text { duration of } \\
\text { procedure }^{34,35} \text {. If } \\
\text { cannot tolerate } \\
\text { this: clindamycin } \\
\text { or amoxycillin. }\end{array}$ & $\begin{array}{l}\text { N/A } \\
\text { Stop within } 24 \text { hours* }\end{array}$ & Medium \\
\hline
\end{tabular}

* Stop within 24 hours indicates administration prior to and during surgery, and doses after surgery up till 24 hours. Inter-dosing interval after surgery is described below.

**Perioperative only indicates administration prior to and during surgery, but no further doses after surgery

\section{Timing of prophylactic antimicrobials:}

Tissue levels of antimicrobials are required at the time of first incision to confer protection from surgical site infection.

Intravenous antimicrobials: administer 30-60 mins prior to first surgical incision

$\mathrm{T}_{\max }$ for individual drugs given by different routes can be used to assess optimal timing to achieve peak serum 
levels at the time of first incision.

\section{Repeat dosing:}

Dosing interval should be measured from the time of the preoperative dose. The dosing interval can be calculated as twice the elimination half-life of the antimicrobial.

Cefazolin: Maintains concentrations above MIC for common skin pathogens (Staphylococcal \& Streptococcal species) for 4 hours, ${ }^{36}$ however 2 hourly administration (twice elimination $1 / 2$ life) may be required for E.coli. ${ }^{37}$

Amoxycillin: 2 hours ${ }^{38}$

\section{Other factors to consider:}

Clip hair less than 4 hours before surgery ${ }^{30}$

Minimise number of people in surgical theatre ${ }^{31}$

Consider use of surgical safety checklist. Use of these tools has reduced surgical complications from $17 \%$ to $7 \%$ (surgical site infections from $5 \%$ to $1.4 \%)^{23}$

\section{A special mention - surgical treatment of cranial cruciate ligament rupture:}

As many research papers have been produced addressing cranial cruciate repair, and often include conflicting advice, this was treated as a special case in these guidelines.

Tibial tuberosity advancement (TTA): Peri-operative prophylaxis only, no evidence for post-operative therapy ${ }^{39}$.

Tibial plateau levelling osteotomy (TPLO): Peri-operative prophylaxis only ${ }^{40,41}$. Studies that have shown 
reduced post-operative surgical site infections have had prophylactic therapy protocols that were unlikely to result in the necessary serum antimicrobial levels at the time of the first incision. ${ }^{42}$ Additional studies did not report whether the timing of antimicrobial therapy was at the surgeon's discretion, ${ }^{43-45}$ thereby introducing unacceptable confounding bias. Careful attention should be paid to the timing of prophylactic antimicrobial therapy.

TightRope: Peri-operative prophylaxis only ${ }^{41}$. 
Table 2. Results of the guideline appraisal using the adapted Appraisal of Guidelines for Research and Evaluation version 2 (AGREE II) tool.

\begin{tabular}{|c|c|c|c|c|}
\hline & Domain & Question & $\begin{array}{l}\text { Question } \\
\text { score (\%) }\end{array}$ & $\begin{array}{c}\text { Scaled } \\
\text { domain } \\
\text { score (\%) }\end{array}$ \\
\hline 1 & $\begin{array}{l}\text { Scope and } \\
\text { purpose }\end{array}$ & $\begin{array}{l}\text { The overall objective of the guideline is specifically } \\
\text { described } \\
\text { The disease condition covered by the guideline is } \\
\text { specifically described } \\
\text { The species to which the guideline is meant to apply is } \\
\text { specifically described }\end{array}$ & $\begin{array}{l}81 \\
90\end{array}$ & 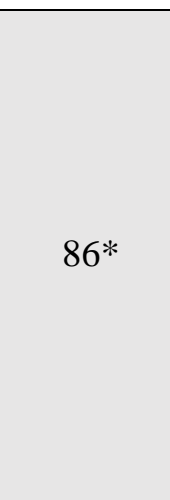 \\
\hline 2 & $\begin{array}{l}\text { Stakeholder } \\
\text { involvement }\end{array}$ & $\begin{array}{l}\text { The guidelines development group includes individuals } \\
\text { from all relevant professional groups } \\
\text { The views and preferences of veterinarians have been } \\
\text { sought } \\
\text { The target users of the guideline are clearly defined }\end{array}$ & $\begin{array}{l}75 \\
92\end{array}$ & 73 \\
\hline 3 & $\begin{array}{c}\text { Rigour of } \\
\text { development }\end{array}$ & $\begin{array}{l}\text { Systematic methods were used to search for evidence } \\
\text { The criteria for selecting the evidence are clearly } \\
\text { described } \\
\text { The strengths and limitations of the body of evidence } \\
\text { are clearly described } \\
\text { The methods for formulating the recommendations are } \\
\text { clearly described } \\
\text { The health benefits, side-effects, and risks have been }\end{array}$ & $\begin{array}{l}91 \\
87 \\
88\end{array}$ & $80^{*}$ \\
\hline
\end{tabular}


There is an explicit link between the recommendations

and the supporting evidence

The guideline has been externally reviewed by experts prior to its publication

The procedure for updating the guideline is provided

$4 \quad$ Clarity of The recommendations are specific and unambiguous

presentation The different options for management are clearly

presented

Key recommendations are easily identifiable

5 Applicability The guideline describes the facilitators of and barriers

to its application

The guideline provides advice and/or tools on how the recommendations can be put into practice

The potential resource implications of applying the recommendations have been considered

The guideline presents monitoring and/or auditing criteria

6 Editorial The views of the funding body have not influenced the 95

independence content of the guidelines

Competing interests of the guideline development group members have been recorded and addressed

Overall Rate the overall quality of the guidelines

* These domains were updated following feedback from appraisers 


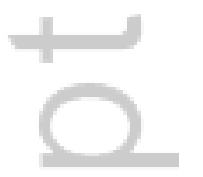




\section{University Library}

\section{- M M N E R VA A gateway to Melbourne's research publications}

Minerva Access is the Institutional Repository of The University of Melbourne

\section{Author/s:}

Hardefeldt, LY;Crabb, HK;Bailey, KE;Johnstone, T;Gilkersoe, JR;Billman-Jacobe,

$\mathrm{H}$;Browning, GF

Title:

Appraisal of the Australian Veterinary Prescribing Guidelines for antimicrobial prophylaxis for surgery in dogs and cats

Date:

2019-07-08

Citation:

Hardefeldt, L. Y., Crabb, H. K., Bailey, K. E., Johnstone, T., Gilkersoe, J. R., Billman-Jacobe, H. \& Browning, G. F. (2019). Appraisal of the Australian Veterinary Prescribing Guidelines for antimicrobial prophylaxis for surgery in dogs and cats. Australian Veterinary Journal, 97 (9), pp.316-322. https://doi.org/10.1111/avj.12848.

Persistent Link:

http://hdl.handle.net/11343/286128 